\title{
EVALUATION OF FUTURE RIVER DISCHARGE UNCERTAINTIES IN THE INDOCHINA PENINSULA SIMULATED BY MULTI-PHYSICS ENSEMBLE EXPERIMENTS USING TWO-WAY ANOVA
}

\author{
Patinya HANITTINAN ${ }^{1}$, Yasuto TACHIKAWA ${ }^{2}$, Yutaka ICHIKAWA ${ }^{3}$, \\ and Kazuaki YOROZU 4
}

\footnotetext{
${ }^{1}$ Student Member of JSCE, Graduate Student, Dept. of Civil and Earth Resources Eng., Kyoto University, Kyoto 615-8540, Japan

${ }^{2}$ Member of JSCE, Prof., Dept. of Civil and Earth Resources Eng., Kyoto University, Kyoto 615-8540, Japan

${ }^{3}$ Member of JSCE, Assoc.Prof., Dept. of Civil and Earth Resources Eng., Kyoto University, Kyoto 615-8540, Japan

${ }^{4}$ Member of JSCE, Assist. Prof., Dept. of Civil and Earth Resources Eng., Kyoto University, Kyoto 615-8540, Japan
}

\begin{abstract}
This study focuses on evaluating uncertainties in river discharge projection in the Indochina Peninsula using nine ensemble experiments, which are combination of three different cloud convection schemes and three different sea surface temperatures (SSTs) change patterns. The nine river flow ensemble data were obtained using the outputs in the future climate (2075-2099) of the 60-km-mesh MRI-AGCM 3.2H under the high concentration RCP8.5 scenario. To clarify which factor of the use of different SST pattern changes or different cloud convection schemes contributes to the projected uncertainty on river discharge, the two-way analysis of variance (ANOVA) without interaction between multiple cloud convection schemes and multiple SST patterns was applied to the nine ensemble projections. The results reveal that the uncertainty in the future river discharge projection in the Indochina Peninsula derived mainly from the differences in the convection schemes.
\end{abstract}

Key Words: Indochina Peninsula, MRI-AGCM, ANOVA, uncertainties, river discharge, $1 K-F R M$

\section{INTRODUCTION}

In the Intergovernmental Panel on Climate Change Fifth Assessment Report (IPCC AR5) published in $2014^{1)}$, it was concluded that the human influence on the climate system is clear, and recent anthropogenic emissions of greenhouse gases are the highest in history. Recent climate changes are likely to cause widespread impacts on human, climate systems, hydrological cycle, and associated extremes such as floods and drought ${ }^{2,3)}$.

Currently, the studies on analyzing runoff/streamflow projection under climate change can employ the land surface models (LSMs), hydrological models forced by bias-corrected input forcing data from Global Circulation Models (GCMs), or directly use the runoff outputs from $\mathrm{GCMs}^{2), 4)}$, to simulate river discharge and assess the impact of climate change on water resources. Despite its role as fundamental tools and continuing improvements in climate modeling in recent years, three major uncertainties in GCMs still remain, namely, internal variability, future emission scenarios which arising from the limitations of our understanding of how future greenhouse gases emission will change, and model uncertainties ${ }^{5}$. The prospective ways to deliver evaluations and reductions in total prediction uncertainty have been developed, in which multi-model ensemble and multi-physics ensemble are two main approaches which have been cited most frequently ${ }^{5}$. There have been some studies that utilizes the latter method, which combines different physical parameterizations and sea-surface temperature experiments ${ }^{6,7}$, with aim to quantify uncertainty in projections of future river discharge under climate change by using large and diverse sets of GCMs realizations to characterize uncertainty and probability distribution functions (PDFs) of extreme events at regional scale. 
In recent study ${ }^{6}$, analysis on the effect different components of climate models tended to focus on its directly related hydrologic variables, e.g., precipitation, total runoff, which are both natural choice and major input for hydrologic cycle.

In general, impacts of climate change on surface water distribution are most clearly represented by the state of river discharge. For instance, occurrence of floods almost always followed by big increase in the discharge and water level; on the contrary, major drought event also frequently happened after prolonged period of exceptionally low flow. Therefore, analysis of its impact to river discharge will yield significant values to practical application. Unfortunately, simulated river discharge from a flow routing model is resulted from sophisticated incorporation of topological information, which made it highly complex and difficult to interpret.

The motivating question behind this study is how we can, at least, increase trustworthiness of probabilistic analysis of future impact of river discharge by combining results of multiple datasets. However, relying only on large amount of datasets may not be sufficient, because the data from different physics ensemble might not come from the same population. Therefore, a further statistical test to examine whether the means of GCMs datasets come from identical or different populations is essential and should be a prerequisite to consider merging of GCM datasets to increase a number of sample size.

To examine statistical difference of river flow projections using GCM outputs with different cloud convection schemes and different sea surface temperatures (SSTs), we conducted the two-way Analysis of Variance (ANOVA) to projected river discharge using the latest $60-\mathrm{km}$-mesh MRI-AGCM $3.2 \mathrm{H}$ with nine ensemble experiments. The Indochina Peninsula (Fig.1) was chosen as a study area due to its projected risk of flood in the future ${ }^{3)}$, and mostly comprised of developing countries, which makes it particularly vulnerable to the impact of climate change ${ }^{1)}$.

\section{MODELING APPROACHES}

\section{(1) River Flow Routing Model}

A distributed, kinematic-wave flow routing model, $1 \mathrm{~K}-\mathrm{FRM}^{2}$, was based on a watershed topography model, generated from processing of the scale-free global streamflow network datasets ${ }^{3)}$ with spatial information of 5 arc-minutes. The flow direction is defined using the 8-direction method, which assigns flow from each grid cell to one of its 8 neighbors, in the direction with the steepest downward slope to immediate neighboring cell. The total runoff outputs from GCM are then routed by the kinematic wave theory at each flow element according with the flow direction information. The one-dimensional kinematic wave equations for each cell are discussed in Duong et al. ${ }^{2}$.

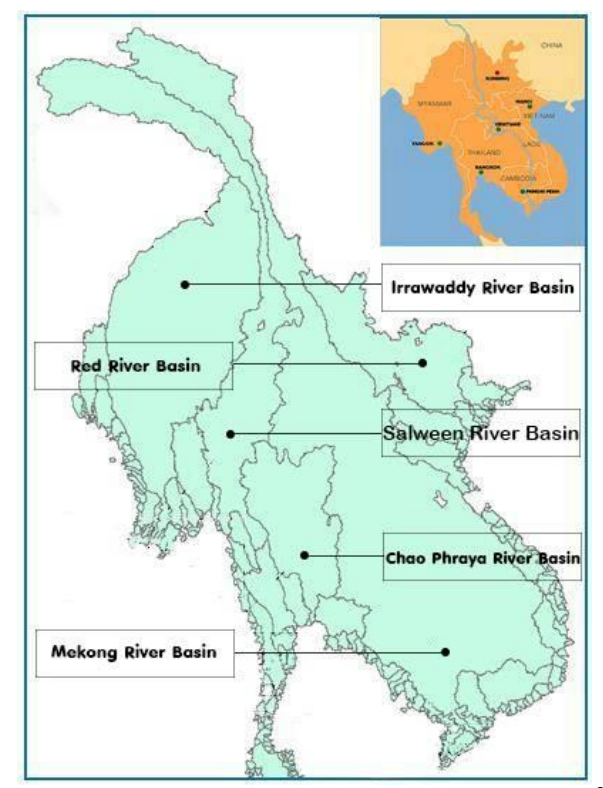

Fig. 1 The study area, Indochina Peninsula region ${ }^{2)}$.

\section{(2) General Circulation Model}

The GCM used in this study is MRI-AGCM 3.2 $\mathrm{H}^{5)}$. It has a $60-\mathrm{km}$ spatial resolution, jointly developed by the Japan Meteorological Agency (JMA) and the Meteorological Research Institute (MRI). The total runoff data retrieved from the GCM was used as input for the flow routing model with two 25-years periods: 1979-2003 (present climate) and 2075-2099 (future climate). The data used for future projection was based on the high concentration RCP 8.5 scenarios, under nine multi-physics and multi-SSTs ensemble projections (i.e., combination of 3 different cumulus schemes and 3 different sea surface temperature (SST) change patterns.

\section{(3) Analysis of Variance (ANOVA)}

Statistical significance of the differences among two group means, namely cumulative convection schemes and SST patterns, were analyzed and tested using the two-way ANOVA without interaction ${ }^{8}$. This statistical analysis decomposes the total variance of the 9 ensemble projections into three components: the variance due to the different SST changes, the variance due to the different cumulus convection schemes, and residual, assuming that the effect from the two factors is mutually independent. The data structure of the two-way ANOVA without interaction is modeled as follows:

$$
x_{i j}=\mu+\alpha_{i}+\beta_{j}+\varepsilon_{i j}
$$


where $x_{i j}$ is a sample data; $\mu$ is the overall mean; $\alpha_{\mathrm{i}}$ and $\beta_{\mathrm{j}}$ are the $1^{\text {st }}$ and $2^{\text {nd }}$ explanatory variables; and $\varepsilon_{\mathrm{ij}}$ are the independent and identically distributed (iid) zero mean normal random errors. To prove whether the different mean values are significant on the total mean, the total amount of variation, denoted as a sum of squares (SS) is calculated by the following equation:

$$
S_{T}=S_{A}+S_{B}+S_{E}
$$

where $S_{T}$ is a total sum of squares, $S_{A}$ is a sum of squares for the river discharge under different cloud convection schemes, $S_{B}$ is a sum of squares for the river discharge under different SST patterns, and $S_{E}$ is called residual of the river discharge.

In this paper, four different cases of the future river discharge in the Indochina Peninsula were analyzed, which were: a) the maximum discharge, b) the average annual maximum discharge, c) the average discharge, and d) the minimum discharge in the future 25 years, respectively.

In the case of the two independent variables under consideration, we constructed the ANOVA table (see Table 1), with $a$ members of $1^{\text {st }}$ variable and $b$ members of $2^{\text {nd }}$ variables, resulting in total $a$ $\times b$ members, where $a=3$ for three cloud convection schemes AS, YS, and $\mathrm{KF}^{6}$; and $b=3$ for three sea surface temperature patterns Cluster 1, 2 and $3^{6,7)}$.

Based on the aforementioned assumptions and ANOVA variables (Table 1), the sum of square for each independent variable can be computed as follows:

$$
\begin{aligned}
& S_{T}=\sum_{i=1}^{a} \sum_{j=1}^{b} x_{i j}^{2}-\frac{\left(\sum_{i=1}^{a} \sum_{j=1}^{b} x_{i j}\right)^{2}}{a b} \\
& S_{A}=\frac{\left(\sum_{j=1}^{b} x_{1 j}\right)^{2}+\left(\sum_{j=2}^{b} x_{2 j}\right)^{2}+\ldots+\left(\sum_{j=1}^{b} x_{a j}\right)^{2}}{b} \\
& -\frac{\left(\sum_{i=1}^{a} \sum_{j=1}^{b} x_{i j}^{2}\right)^{2}}{a b}
\end{aligned}
$$$$
S_{B}=\frac{\left(\sum_{i=1}^{a} x_{i 1}\right)^{2}+\left(\sum_{i=2}^{a} x_{i 2}\right)^{2}+\ldots+\left(\sum_{i=1}^{a} x_{1 b}\right)^{2}}{a}
$$$$
-\frac{\left(\sum_{i=1}^{a} \sum_{j=1}^{b} x_{i j}^{2}\right)^{2}}{a b}
$$

In this study, by assuming no correlation between the two factors A and B, then:

$$
S_{E}=S_{T}-S_{A}-S_{B}
$$

Then, from eq. (3), (4), (5), and (6), we can determine mean square of $\mathrm{A}\left(M S_{A}\right)$, mean square of $\mathrm{B}\left(M S_{B}\right)$, and mean square of within group variance $\left(M S_{E}\right)$. Subsequently, statistical significance of the difference of each group mean to the total mean was computed by conducting F-test by calculating ratios of the mean square for each explanatory variable with $M S_{E}$ as shown in tabulated form (see Table 2). There are two separate null hypotheses when conducting a two-way ANOVA. Thus, two F ratios are calculated and tested for statistical significance, namely main effect for multi-SSTs and clould convection schemes. Hence, the criterion for acceptance of rejection of null hypotheses are given by Eq. (7) and (8):

$$
\begin{aligned}
& \frac{M S_{A}}{M S_{E}} \geq F(a-1,(a-1)(b-1) ; \alpha) \\
& \frac{M S_{B}}{M S_{E}} \geq F(b-1,(a-1)(b-1) ; \alpha)
\end{aligned}
$$

\begin{tabular}{|c|c|c|c|c|c|}
\hline & $B_{1}$ & $\boldsymbol{B}_{2}$ & $\ldots$ & $\boldsymbol{B}_{b}$ & $\operatorname{Sum}(\boldsymbol{b})$ \\
\hline $\mathbf{A}_{1}$ & $x_{11}$ & $x_{12}$ & $\ldots$ & $x_{1 b}$ & 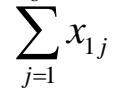 \\
\hline $\mathbf{A}_{2}$ & $x_{21}$ & $x_{22}$ & $\ldots$ & $x_{2 b}$ & $j$ \\
\hline$\cdots$ & $\ldots$ & $\cdots$ & $\ldots$ & $\ldots$ & \\
\hline $\mathbf{A}_{\mathrm{a}}$ & $x_{a 1}$ & $x_{a 2}$ & $\ldots$ & $x_{a b}$ & \\
\hline $\operatorname{Sum}(\mathbf{a})$ & $=1$ & $=1$ & $\ldots$ & $=1$ & $i=1 \quad j=1$ \\
\hline
\end{tabular}

where $(a-1)$ is the degree of freedom $(\mathrm{dF})$ for variance of cumulus cloud convection schemes; $(b-1)$ is the degree of freedom for variance of multiple sea surface temperature patterns; and $\alpha$ is the significant level, which equals 0.01 in this study.

Table 1 ANOVA tables and its associated variables in each cell.

Table 2 ANOVA formulae in tabulated form

\begin{tabular}{c|cccc}
\hline & SS & dF & Mean sum of square & F \\
\hline $\mathbf{A}_{\mathbf{i}}$ & $\mathrm{S}_{\mathrm{A}}$ & $a-1$ & $M S_{A}=\frac{S_{A}}{a-1}$ & $F_{A}=\frac{M S_{A}}{M S_{E}}$ \\
$\mathbf{B}_{\mathbf{j}}$ & $\mathrm{S}_{\mathrm{B}}$ & $b-1$ & $M S_{B}=\frac{S_{B}}{b-1}$ & $F_{B}=\frac{M S_{B}}{M S_{E}}$ \\
& $\mathrm{~S}_{\mathrm{E}}$ & $(a-1)(b-1)$ & $M S_{E}=\frac{S_{E}}{(a-1)(b-1)}$ & \\
\hline
\end{tabular}




\section{RESULTS}

\section{(1) Contribution of Cloud Convection Schemes to Total Variance}

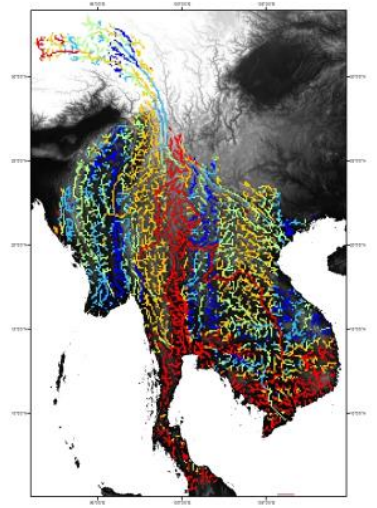

(a)

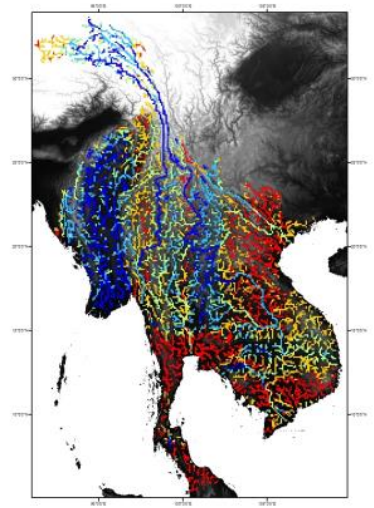

(c)

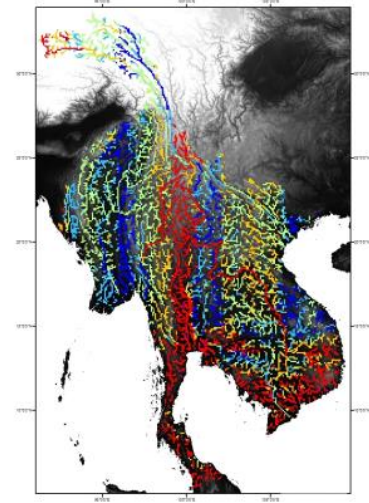

(b)

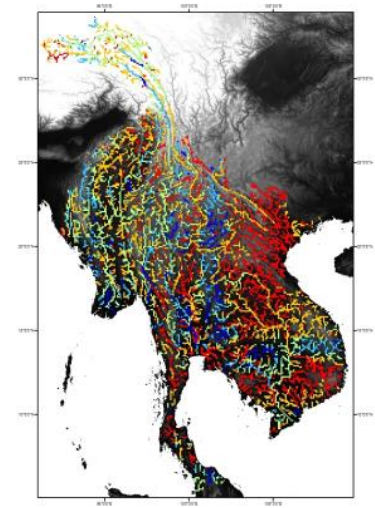

(d)

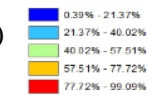

Figure 2 Contribution from the different cloud convection schemes to the total variance of a) the maximum discharge, b) the average annual maximum discharge, c) the mean discharge, and d) the minimum discharge - in the future 25 year.

Fig. 2 presents spatial distribution mapping of the contribution of cloud convection schemes to the total mean variance in the future climate at the Indochina Peninsula under 4 cases. In the first 2 cases, the clearest contributions cloud convection schemes $\left(S_{A} / S_{T}=77-99 \%\right)$ is commonly found in the middle to northern part of the Chao Phraya River Basin, Southern River Basin region in Thailand, and the southern part of Mekong Delta. On the other hand, the Salween Basin is less contributed by the schemes, with $0.39-21.37 \%$ to total variance of mean (see Fig. 2a, Fig. 2b).

For the case c), the cloud convection schemes contribution signals is strong in the lower Chao Phraya, Southern Basin region in Thailand, Mekong Delta, and the Red River Basin in Vietnam. Meanwhile, the scheme signals is projected to be exceptionally weak in the Irrawaddy Basin in

Myanmar, somewhat weak in eastern Chao Phraya Basin, and up to the middle region of Mekong River Basin, with contribution ratio between 0.40 $21.40 \%$.

For the case d), we found that the cloud convection schemes made a sizable contribution to the total variance of minimum river discharge at the Red River Basin, and the Mekong Delta, with proportion between 77-99\%. However, the contribution is less significant in the other basins, e.g., Irradwaddy, Salween, the Chao Phraya Basin, and the Northern Mekong Basin (see Fig. 2c, Fig. 2d). According to the results, it is notable that most regions clearly show consistency in the spatially-distributed signals on cloud schemes contribution to total variance for the former 3 cases (Fig. 2a, Fig. 2b, Fig. 2c), but less so in the fourth case (Fig. 2d).

\section{(2) Contribution of Sea Surface Temperature Patterns to Total Variance}

For multiple SST patterns (see Fig.3), we also presented its contribution to the total variance of future river discharge in the Indochina Peninsula. In the first two cases, the SSTs showed little role in contributing to the total variance in river discharge in the Chao Phraya Basin, the Red River Basin, and Mekong Delta. The SSTs also showed similar signals in case b), but some differences occurred in the Salween Basin, in which case b) showed stronger contribution from the SSTs patterns to the total variance of river discharge than case a). Figs. 3c) and 3d) show signals from SSTs in case c) and d), which can be seen that the effect of weak signals from SSTs in the lower Chao Phraya Basin, the middle part of Mekong, and majority of the Red River Basin are clearly visible.

For case d), overwhelmingly weak signals of SSTs are vividly presented for most region of the Indochina Peninsula. The results of the different SSTs mostly point to a strong, consistent response across all cases in most of the basin, except for the Irrawaddy and Salween Basin, which showed contradicted SSTs patterns with the other basins; and also has 3 out of 4 similar results in all cases.

The results of the two-way ANOVA in all four cases (Fig. 3a-Fig. 3d) indicate that the variance due to different SST patterns play relatively smaller proportion to the total variance of river discharge in majority of the region in the Indochina Peninsula compared with the contribution from the variance due to the different cloud convection parameterization schemes. Next, statistical significance of the proportion of the total variance of each component will be assessed through calculation of F-statistics, which its outcomes shall 
help accounts for both the major sources of future river discharge variance in the Indochina Peninsula.

\section{(3) Testing for Statistical Significance of the Convection Schemes and SSTs Patterns}

For the first two cases (see Fig.4a and Fig. 4b), most of the Irrawaddy, Salween, and the Red River Basin, results are clearly indicated that effect of various cloud convection schemes to the total variance of river discharge is not significant. However, different cloud schemes appeared playing statistically significance role for the in the Chao Phraya Basin, and the Mekong River.

Fig. 4c) indicates that for the lower Chao Phraya Basin and the Mekong Delta, the effect of different convection schemes has made statistically significant impacts on the total variance of river discharge, based on rejection of null hypotheses. Meanwhile, the effect of the schemes is not quite as prominent as Fig. 4d), which most regions show little statistical significance to its total variance. For Fig. 5a) and 5b), results are widely showed that multiple SSTs affect to the total variance of river discharge are not significant for most of the region. One important exception is found at the main Mekong River. For Figs. 5c) and 5d), results are largely similar with Figs. 5a) and 5b), where multiple SSTs are projected insignificant to the river discharge's total variance.

The implication of hydrologic analysis for the results in Fig. 4 and Fig. 5 can be summarized as follows:

1) In the region where null hypotheses of either multiple cloud convection schemes or SST patterns are rejected means that these factors contribute significantly to the total variance of river discharge, which indicates that combining the ensemble river flow data for hydrologic frequency analysis in the rejection region might cause significant uncertainties because it came from the different statistical population.

2) In the region where null hypotheses of either multiple cloud convection schemes or SST patterns are not rejected indicates the opposite outcome, which means these factors are not going to significantly affect the total variance of projected river discharge. Thereby, the ensemble of river discharge datasets in non-rejected region could be combined for the hydrologic frequency analysis, with fewer uncertainties, and should leads to more credible impact assessment under changing climate.

3) The overall results of F-test demonstrate that the cloud convection schemes dominate projected uncertainties of river discharge in the Indochina region.

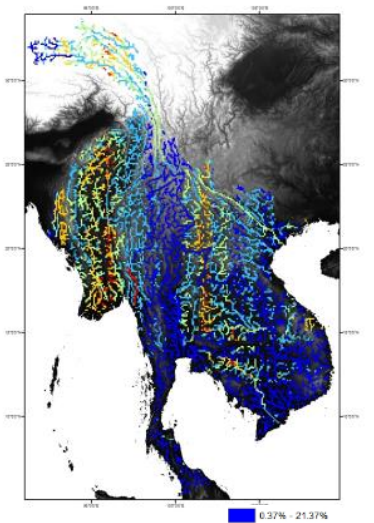

(a)

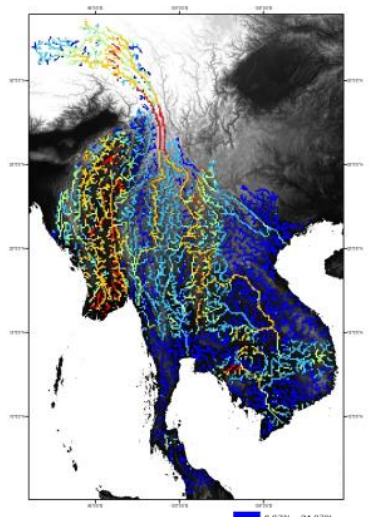

(c)

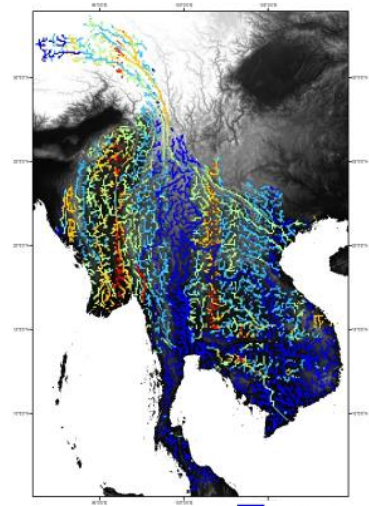

(b)

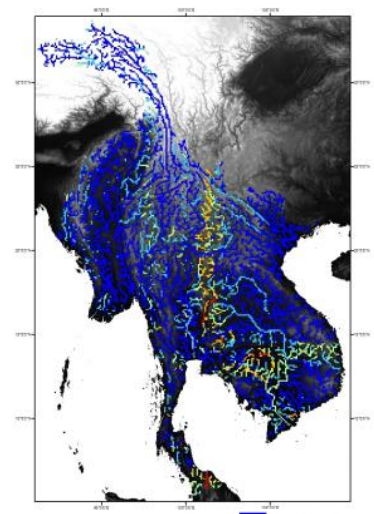

(d)

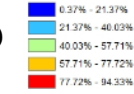

Figure 3 Contribution from the different SST patterns to the total variance of (a) the maximum discharge, (b) the average annual maximum discharge, (c) the annual mean discharge, and (d) the minimum discharge - in the future 25 years.

\section{DISCUSSIONS and CONCLUSIONS}

According to Endo et al. ${ }^{6}$, the results of the ANOVA based on the 60-km MRI-AGCM 3.2H ensemble precipitation projections show the significant effect of each factor at 5\% level to its total variance. The results have revealed evidences that for extreme and average precipitation indices, variances arising from the use of the different cumulus convection schemes are generally larger than those arising from the use of the different SST patterns in most of the Asia Pacific, especially in the Indochina Peninsula, Indian Peninsula, and mainland China. Thus, the uncertainties in projected changes in precipitation are derived mainly from differences in the cloud convection schemes employed in these areas.

Due to the nature of the runoff data used as input for the flow routing model, it is strongly related to projected precipitation data. Therefore, we argue that proportions of the flow area in which the cloud schemes dominate the uncertainties of the river discharge are substantially larger than the SSTs-dominated area (see Fig. 4 and Fig. 5), which are compliment with the results of Endo et al. ${ }^{6}$ 


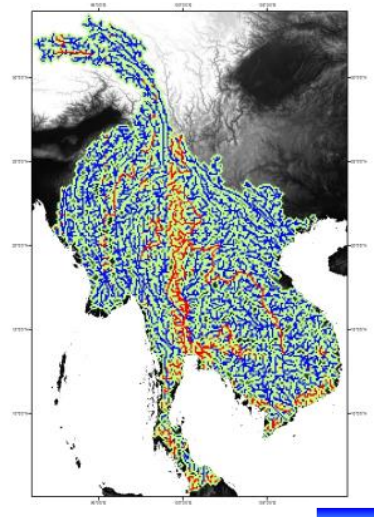

(a)

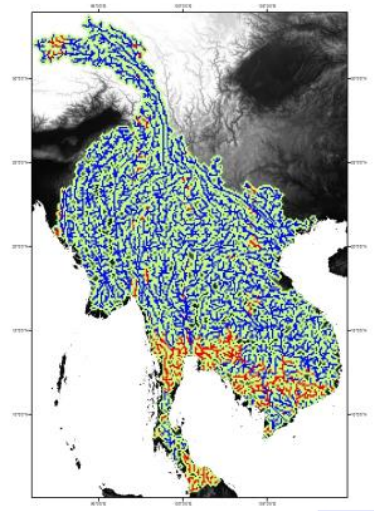

(c)

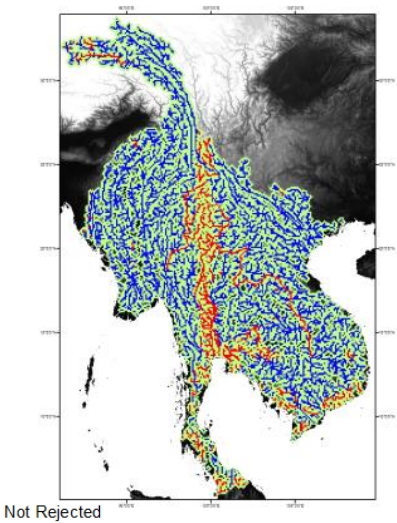

(b)

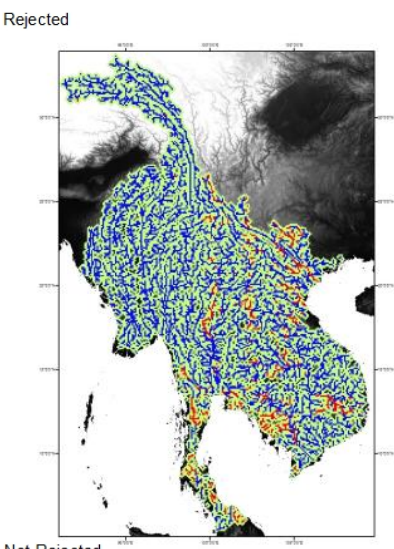

(d)

Figure 4 statistical significance test using F-value of the different cloud convection schemes for (a) the maximum discharge, (b) the average annual maximum discharge, (c) the mean discharge, and (d) the minimum discharge - in the future 25 years

In this study, we clarify which factor of the use of different SST patterns or different cloud convection schemes contributes more to the projected uncertainty on river discharge by using the two-way analysis of variance (ANOVA) for the nine ensemble projections by the $60-\mathrm{km}$ model, based on the established F-statistics criterion on accepting null hypotheses. The results reveal that the uncertainty in the future river discharge in the Indochina Peninsula derived mainly from the differences in the convection schemes.

ACKNOWLEDGEMENTS: This research was conducted under the framework of the "Precise Impact Assessments on Climate Change" supported by the SOUSEI Program of the Ministry of Education, Culture, Sports, Science, and Technology.

\section{REFERENCES}

1) IPCC: Climate Change: Synthesis Report. Contribution of Working Groups I, II and III to the Fifth Assessment Report of the Intergovernmental Panel on Climate Change [Core Writing Team, R.K. Pachauri and L.A. Meyer (eds.)]. IPCC, Geneva, Switzerland, 151 pp, 2014.

2) Duong, D. T., Tachikawa, Y., Shiiba, M., Yorozu, K.: River Discharge changes In the Indochina Peninsula

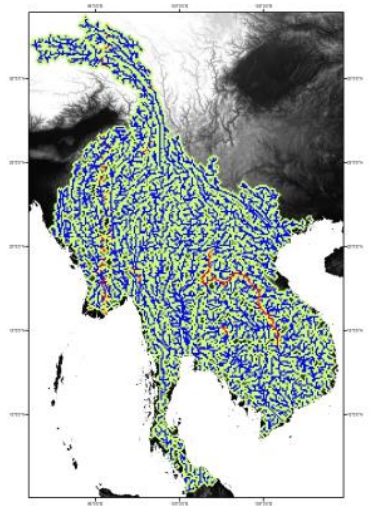

(a)

(c)

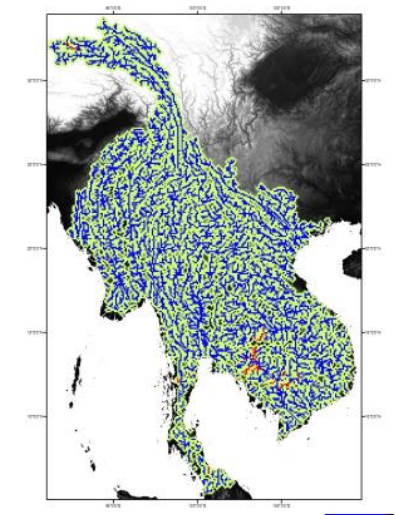

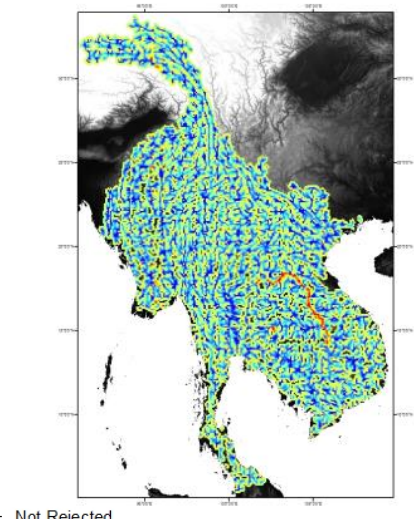

(b)

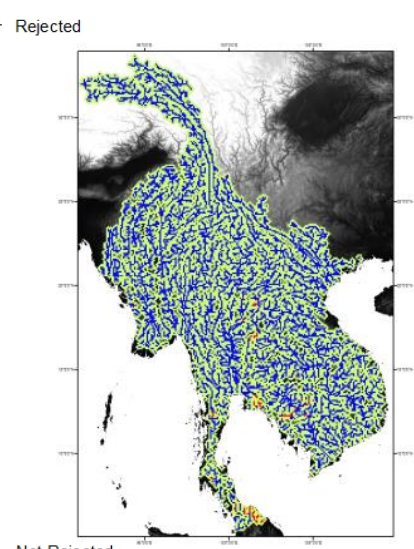

(d)
Figure 5 statistical significance test using F-value of the different sea surface temperature patterns for (a) the maximum discharge, (b) the average annual maximum discharge, (c) the mean discharge, and (d) the minimum discharge - in the future 25 years

Region Projected Using MRI-AGCM and MIROC 5. Journal of Japan Society of Civil Engineers, Ser. B1 (Hydraulic Engineering), Vol. 69, No. 4, I_37-I_42, 2013.

3) Masutani, K., Akai, K., Magome, J. (2006) A new scaling algorithm of gridded river networks, Japan Society of Hydrology and Water Resources, 19 (2), 139 - 150 (in Japanese).

4) Hirabayashi, Y., Mahendran, R., Koirala, S., Konoshima, L., Yamazaki, D., Watanabe, S., Kim, H., and Kanae S. Global flood risk under climate change Nat. Clim. Change 3, 816-21, 2013.

5) Hawkins, E. and Sutton, R.: The Potential to Narrow Uncertainty in Regional Climate Predictions, B. Am. Meteorol. Soc., 90, 1095-1107, 2009.

6) Endo, H., Kitoh, A., Ose, T., Mizuta, R., and Kusunoki, S.: Future changes and uncertainties in Asian precipitation simulated by multiphysics and multi-sea surface temperature ensemble experiments with high-resolution Meteorological Research Institute atmospheric general circulation models (MRI-AGCMs), J. Geophys. Res., 117, D16118, 2012.

7) Mizuta, R., Arakawa, O, Ose, T, Kusunoki, S., Endo, H., and Kitoh, A.: Classification of CMIP5 future climate responses by the tropical sea surface temperature changes. SOLA, 10, 167-171, 2014, doi:10.2151/sola.2014-035.

8) Storch, H. V., and Zwiers, F.W.: Statistical Analysis in Climate Research, Cambridge Univ. Press, Cambridge, U.K., 2012.

(Received September 30, 2015) 